Case Report

\title{
Acute Acalculous Cholecystitis Associated with Epstein-Barr Infection: A Case Report and Review of the Literature
}

\author{
Konstantinos Ntelis (D), ${ }^{1}$ Dimosthenis Mazarakis, ${ }^{2}$ Apostolos Sapountzis, ${ }^{3}$ Dimitra Zissi, ${ }^{4}$ \\ Sophia Sparangi, ${ }^{2}$ Nikoletta Xidia, ${ }^{2}$ and Dimitrios Velissaris ${ }^{5}$
}

${ }^{1}$ Department of Rheumatology, General Hospital of Patras "St. Andrews", Patras, Greece

${ }^{2}$ Department of Internal Medicine, General Hospital of Kalamata, Kalamata, Greece

${ }^{3}$ Department of Gastroenterology, General Hospital of Kalamata, Kalamata, Greece

${ }^{4}$ Department of Microbiology, General Hospital of Sparta, Sparta, Greece

${ }^{5}$ Department of Internal Medicine, University Hospital of Patras, Rion, Greece

Correspondence should be addressed to Konstantinos Ntelis; kosdelis@gmail.com

Received 17 February 2019; Accepted 6 January 2020; Published 25 January 2020

Academic Editor: Walter Zidek

Copyright ( $\odot 2020$ Konstantinos Ntelis et al. This is an open access article distributed under the Creative Commons Attribution License, which permits unrestricted use, distribution, and reproduction in any medium, provided the original work is properly cited.

\begin{abstract}
The most common cause of acute cholecystitis (ACC) is cholelithiasis. Acute acalculous cholecystitis (AAC) is well documented in the literature related with critical illness, but viral causes such as cytomegalovirus (CMV) and Epstein-Barr virus (EBV) have also been reported. We present a rare manifestation of EBV infection, reporting a case of a 15-year-old female suffering from acute acalulous cholecystitis, and we review the relevant literature. Clinicians should be aware of this rare complication of EBV infection and properly exclude it in young patients with cholecystitis.
\end{abstract}

\section{Introduction}

Infectious mononucleosis (IM) is a common disease affecting mainly adolescents and young adults, usually causing fever, sore throat, fatigue, lymphadenopthy, and splenomegaly. The etiology of the disease is a widely disseminated DNA virus, the Epstein-Barr virus (EBV), a member of the herpes virus family. The genome of the virus consists of approximately 85 genes located on a doublestrand DNA helix of 177.000 pair of bases [1]. It is estimated that $90 \%$ of the global population has been exposed to the virus, but the vast majority of the individuals remain asymptomatic during the infection. When symptoms are present, they are usually mild and the syndrome is selflimited.

EBV has a lymphotropic behavior, primarily affecting $B$ cells and secondarily epithelial cells. In vitro, the expression of the viral genome inside the affected lymphocytes gives them the potential to become immortal [2]. Additionally, the virus has the ability of latent infection of a subset of memory B cells; therefore, it can remain lifelong hidden in lymphoid cells, initiating an interplay between the virus and immune system response [3]. The dysregulation of this interaction between the virus and the immune response gives a rationale for the association of EBV infection with certain autoimmune conditions $[4,5]$. In addition, the expression of the latent genes of the virus in the infected cells is considered the key factor for its oncogenic activity [2].

As mentioned above, EBV infection has an asymptomatic course or it is accompanied by symptoms of IM. The main laboratory finding in IM is the extreme lymphocytosis, due to the effect of the virus in the specific CD8 T cells. The infection usually resolves without sequelae, but in a minority of cases, severe complications such as airway obstruction, meningoencephalitis, hemolytic anemia, thrombocytopenia, and splenic rupture can develop. Hepatic involvement in IM is very common, but cholecystitis is extremely rare. Herein, we report a case of acalculous cholecystitis due to EBV infection and we review the relevant literature. 


\section{Case Report}

A 15-year-old female was hospitalized in the Internal Medicine Department of the General Hospital of Kalamata, Western Greece. Initially, she presented to the emergency department complaining of a 4-day history of low-grade fever up to $38.5^{\circ} \mathrm{C}$, sore throat, mild cough, sharp abdominal pain, mainly in the epigastric area, and nausea. Physical examination revealed sensitivity in palpation in both right and left upper abdomen quadrants, normal bowel sounds, and no abdominal distention. Additionally, bilateral cervical and axillary lymphadenopathy, tonsillar enlargement with exudates, and a palpable spleen were noticed. Liver size was within normal range, and there was no jaundiced colouring of the sclera. Laboratory findings on admission and during hospitalization are shown in Table 1.

Abdominal ultrasound revealed thickening of the gallbladder wall to $20 \mathrm{~mm}$ and pericholecystic edema. Distention of the gallbladder was not evident. The spleen was enlarged to $16 \mathrm{~cm}$, and the liver size was within upper normal limits. No stones or dilatation of the biliary tract were reported. Based on these findings, the diagnosis of acute acalculous cholecystitis was made and the patient was admitted to the Internal Medicine Department for further investigation and treatment. The patient was treated with the administration of intravenous fluids and antibiotics (cefoxitin $1 \mathrm{gr}$ tds and clindamycin $600 \mathrm{mg}$ qds). The patient manifested intense nausea and a couple of vomiting episodes on day 2 and 3 of hospitalization. Her cardiovascular and respiratory function remained stable. At the same time, liver enzymes remained elevated equally to the levels of admission. In the follow-up ultrasound, no remarkable changes were reported. Blood and urine cultures were negative. Serological tests, both heterophile antibody test and IgM antibodies against EBV capsid antigen, confirmed the diagnosis of infectious mononucleosis. Serological tests for hepatitis A, B, C, CMV, HIV, and Toxoplasma Gondi were negative. Seven days after admission, the patient was on a good clinical status, fever was resolved, the appetite had improved, and the abdominal pain had also disappeared. A new ultrasound examination on day 6 of admission revealed a total remission of the previous abnormal findings. The patient was discharged on day 8 in a good clinical status. Reassessment 2 weeks later in the Outpatients clinic of the Hospital revealed no clinical or laboratory abnormalities.

\section{Literature Review}

3.1. Methods. To identify relevant publications of interest, we conducted a PubMed search on December 2018 using the terms "Epstein-Barr, infectious mononucleosis, EBV, and cholecystitis." For the purposes of this review, we limited the search to "Humans" and considered only manuscripts referring to adults. Articles in languages besides English were excluded. We also reviewed the bibliographies of all identified manuscripts to identify additional relevant publications. For the purposes of this review, we included all types of publications, including case reports, case series, and review articles, regardless of publication date.
3.2. Results. From the electronic search, we identified 89 articles published in English language. Fifty-three articles reported pediatric cases (patients below 14 years of age) or were irrelevant to our subject and were removed from our search results. Check for duplicates removed 13 more articles, and finally 23 case reports were left and were included in our review. The manual search returned six more cases. Overall, we collected 29 articles describing 30 cases of AAC due to EBV infection in adult patients. The literature search results are summarized in Table 2 .

Clinical presentation, laboratory and imaging findings, and complications and outcomes of EBV-related AAC have been reviewed extensively in the past in a couple of reviews $[23,30]$. Abdominal pain remains the most common symptom. Sore throat and pharyngitis, lympadenopathy, abdominal tenderness, and Murphy's sign are also common findings. Elevation of ALT, AST, ALP, and bilirubin in various degrees is also reported. The most common imaging finding is an increase in gallbladder wall thickness. From our search, we identified 20 cases in which antibiotics were administered. All but two patients were treated conservatively. One immunosuppressed male patient underwent cholecystectomy, and his course was complicated by acute cholestatic hepatitis, cold agglutinin-associated hemolytic anemia, and pneumonia. Histology findings were not reported [10]. The second patient who underwent surgery was a 25-years-old immunocompromised female [33]. The postoperative course was uncomplicated. The pathology report of the removed gallbladder showed AAC. All patients had a full recovery the following weeks after hospitalization.

Twenty-nine from the 31 adult patients described in the literature were females. Only two patients underwent surgery. In the first patient for whom surgery was performed, operation probably aggravated the patient's course. The patient received high doses of corticosteroids and had a good outcome after 19 days of hospitalization [10]. Another patient who also received corticosteroids improved rapidly [29]. In the second patient who underwent surgery, operation improved her symptoms [33].

Acalculous cholecystitis represents $5-10 \%$ of all cases of cholecystitis [34]. The etiology of acalculous cholecystitis is diverse. Main causes are critical illness, sepsis, trauma, surgery, severe burns, parenteral nutrition, prolonged fasting, cancer, infections (both viral and bacterial), and autoimmune disorders, such as systemic lupus erythematosus and systemic vasculitis $[35,36]$. Viral agents and especially EBV are not considered common causes of acute acalculous cholecystitis, but sporadic cases have been previously described in the literature.

The diagnosis of acute acalculous cholecystitis, especially in critically ill patients, remains a clinical challenge. Clinical and laboratory findings combined with imaging findings will finally lead to diagnosis. Fever and right upper quadrant abdominal pain are the major clinical manifestations. Leucocytosis and abnormal liver tests (AST, ALT, ALP, $\gamma$-GT, and bilirubin) are also present, but not specific for cholecystitis. Ultrasound criteria include gallbladder wall thickness, pericholecystic fluid (halo)/subserosal edema, intramural gashydrops, gallbladder distention, and the 
TABLE 1: Laboratory test results during the course of hospitalization.

\begin{tabular}{|c|c|c|c|c|c|c|}
\hline Day of hospitalization & 1 st & 2nd & $3 \mathrm{rd}$ & 4 th & 5 th & 8th (discharge day) \\
\hline White blood cells $\left(/ \mathrm{mm}^{3}\right)$ & 10.18 & 10.01 & 8.64 & 8.1 & 5.82 & 5.11 \\
\hline Neut $(\%)$ & 16.9 & 13.8 & 20.8 & 14.8 & 17.7 & 24.4 \\
\hline Lymph (\%) & 66.7 & 70.8 & 65.0 & 75.2 & 69.1 & 64.2 \\
\hline $\operatorname{PLT}\left(10^{3} / \mathrm{mm}^{3}\right)$ & 120 & 120 & 140 & 160 & 189 & 177 \\
\hline Hct $(\%)$ & 33.3 & 31.6 & 33.9 & 33.2 & 33.1 & 33.8 \\
\hline AST (IU/L) & 106 & 93 & 95 & & 78 & \\
\hline $\operatorname{ALT}(\mathrm{IU} / \mathrm{L})$ & 217 & 172 & 144 & & 108 & \\
\hline ALP (IU/L) & 421 & 406 & 326 & & 348 & \\
\hline$\gamma-\mathrm{GT}(\mathrm{IU} / \mathrm{L})$ & 177 & 171 & 151 & & 176 & \\
\hline TBIL (mg/dL) & 0.84 & 0.54 & & & & \\
\hline DBIL (mg/dL) & 0.32 & 0.20 & & & & \\
\hline
\end{tabular}

Neut: neutrophils, lymph: lymphocytes, PLT: platelets, AST: aspartate aminotransferase, ALT: alanine aminotransferase, ALP: alkaline phosphatase, $\gamma$-GT: gamma glutamyltransferase, TBIL: total bilirubin, DBIL: direct bilirubin.

presence of echogenic bile. Ultrasound remains the most useful utility for the diagnosis of ACC, but in uncertain cases, computed tomography and cholescintigraphy using ${ }^{99 \mathrm{~m}} \mathrm{Tc}$ are reasonable imaging alternatives to establish the diagnosis [35].

Due to the diverse etiology of AAC, different theories about its pathophysiology have arisen. When ACC is the result of critical illness or surgery, the related mechanisms are hypovolemia, shock, ischemia, and secondary bacterial infection from intestinal Gram-negative bacteria [37]. In cases that AAC follows prolonged fasting or parenteral nutrition, bile stasis is considered the key involved factor [37]. Bile stasis results to increased intraluminal gallbladder pressure and secondary decreased blood perfusion, ischemia, and inflammation. In sepsis, the release of proinflammatory mediators to the systemic circulation, the dissemination of the infectious agent to the bile and the concurrent immunodeficiency might explain the reports of AAC [38]. In cases of autoimmune diseases, ischemia due to visceral vasculitis is the implicating causative agent [39]. Endothelial dysfunction and vasculitis are also implicated in cases that AAC is the result of uncommon infections, such as leptospirosis and scrub typhus $[40,41]$. It is obvious that in a patient with AAC more than one among the aforementioned mechanisms can be present, depending on the patient's underlying disease.

In cases of acalculous cholecystitis due to EBV infection, the pathophysiology still remains obscure. Direct invasion of the gallbladder, as EBV can infect epithelial cells, has been proposed, but this theory has not been clearly proved in the few cases that surgery was performed $[10,23,33,42]$. Fretzayas et al. based on scintigraphic data proposed that cholecystitis due to EBV infection may not represent a true cholecystitis, but rather a billiary dyskenisia [43]. This theory is not fully accepted, as in many cases, there was just a mild elevation of ALP and bilirubin, not compatible with severe biliary pathology [23]. The most intriguing observation reviewing the cases of EBV-related cholecystitis is that, in the vast majority of the cases, the patient's gender is female. The most adequate explanation is that production of eicosanoids, which play a role in the pathogenesis of gallbladder disease, seems to be related to gender and estrogen levels $[23,44]$.

\section{Discussion}

The fact that female gender predisposes for certain autoimmune conditions has provided us the motive to further explore the hypothesis that EBV cholecystitis may represent some kind of autoimmune manifestation of IM, taking in mind the lymphotropic behavior of the virus and the virus interaction with the human immune system. Reviewing the literature, we identified one case of EBV cholecystitis where inflammation of the gallbladder has been accompanied by a skin rash, due to dermal vasculitis. The vasculitis was documented with a biopsy, showing lymphocytic infiltrates surrounding the walls of small vessels in the dermis accompanied by plumping of endothelial cells [29]. Another report of EBV cholecystitis accompanied by renal dysfunction with massive proteinuria referred to a 2-year-old patient. The authors underline the key role of the host immune response to EBV in the extent and degree of clinical features of the primary EBV infection [45]. The hypothesis that EBV cholecystitis is an abnormal immune response to primary EBV infection is also supported by the favorable results that glucorticoids had on the course of acalculous EBV cholecystitis in a couple of complicated cases [10,29].

An adequate number of vasculitis reports caused by EBV infection are identified in the literature [46-51]. It is interesting that some of these cases represent localized forms of vasculitis affecting only a single organ. Barrett et al. published in 2015 the histological findings of seven patients with Epstein-Barr Virus Vulvar Ulceration (Lipschütz Disease). All but one specimen exhibited a lymphocytic arteritis (lymphocytes infiltrating and disrupting the artery wall). A diffuse and/or angiocentric predominately lymphocytic infiltrate was found in all cases [49]. Ulcers finally resolved in a short period, usually without the need of medical intervention.

Viral causes of vasculitis besides EBV are also described in the literature. Based on the severity of the clinical presentation, some of the patients with virus-triggered vasculitis received only supportive treatment, while others received antivirals and glucorticoids. Patients' outcomes were generally positive, suggesting that a benign self-limited course is the natural history of virus-associated vasculitis. This could 
TABLE 2: Clinical and demographic characteristics of the present and previous cases of EBV-related cholecystitis.

\begin{tabular}{|c|c|c|c|c|}
\hline Authors, year & Age (years), sex & Country & Treatment & Surgery \\
\hline 1. Yoshie et al. [6], 2004 & 15 female & Japan & Supportive & No \\
\hline 2. Koch et al. [7], 2007 & 53 female & The Netherlands & Supportive & No \\
\hline 3. Iaria et al. [8], 2008 & 18 female & Italy & Antibiotics & No \\
\hline 4. Pelliccia et al. [9], 2008 & 14 female & Italy & Supportive & No \\
\hline 5. Hagel et al. [10], 2009 & 21 female & Germany & Antibiotics/steroids & Yes \\
\hline 6. Cholongitas et al. [11], 2009 & 19 female & Greece & Supportive & No \\
\hline 7. Yang et al. [12], 2010 & 20 female & Korea & Antibiotics & No \\
\hline 8. Chalupa et al. [13], 2009 & 22 female & Czech Republic & Antibiotics & No \\
\hline 9. Arya et al. [14], 2010 & 16 female & USA & Antibiotics & No \\
\hline 10. Nagdev and Ward [15], 2011 & 18 female & USA & Antibiotics & No \\
\hline 11. Beltrame et al. [16], 2012 & 29 female & Italy & Antibiotics & No \\
\hline 12. Dylewski [17], 2012 & 22 female & Canada & Antibiotics & No \\
\hline 13. Carrascosa et al. [18], 2012 & 22 female & Spain & Supportive & No \\
\hline 14. Strehle et al. [19], 2014 & 14 female & UK & Antibiotics & No \\
\hline 15. Celik et al. [20], 2014 & 48 female & Turkey & Antibiotics & No \\
\hline 16. Gagneux-Brunon et al. [21], 2014 & 18 female & France & Antibiotics & No \\
\hline 17. Gagneux-Brunon et al. [21], 2014 & 20 female & France & Antibiotics & No \\
\hline 18. Pawlowska-Kamieniak et al. [22], 2015 & 17 female & Poland & Antibiotics & No \\
\hline 19. Agergaard and Larsen [23], 2015 & 34 female & Denmark & Antibiotics & No \\
\hline 20. Alkhoury et al. [24], 2015 & 15 female & USA & Supportive & No \\
\hline 21. Branco et al. [25], 2015 & 16 female & Portugal & Antibiotics & No \\
\hline 22. Majdalani et al. [26], 2016 & 16 female & Lebanon & Antibiotics & No \\
\hline 23. Ono et al. [27], 2016 & 33 female & Japan & Antibiotics & No \\
\hline 24. Koufakis and Gabranis [28], 2016 & 21 male & Greece & Supportive & No \\
\hline 25. Sheybani et al. [29], 2016 & 13 female & Iran & Steroids & No \\
\hline 26. Yesilbagz et al. [30], 2017 & 30 female & Turkey & Antibiotics & No \\
\hline 28. Cameron et al. [31], 2018 & 18 female & Canada & Supportive & No \\
\hline 29. Hohn et al. [32], 2018 & 24 male & Germany & Supportive & No \\
\hline 30. Rezkallah et al. [33], 2018 & 25 female & USA & Supportive & Yes \\
\hline 31. Present case & 15 female & Greece & Antibiotics & No \\
\hline
\end{tabular}

be another clue that comes to an agreement with the benign course of the patients with EBV cholecystitis, such as described in our patient. In addition, single organ gallbladder vasculitis is a well-described form of localised vasculitis [52]. Viruses such as HBV and HCV have been identified as causative agents in some of these cases. It would be reasonable to speculate that an analogous mechanism could explain gallbladder involvement in cases of EBV-associated acalculous cholecystitis.

We report herein the case of an acalculous cholecystitis in a female adolescent, and we support the hypothesis that EBV-related vasculitis may be the underlying pathogenetic mechanism. Therefore, treatment with glucorticoids could be a useful therapeutic option. The lack of histopathology specimens makes our hypothesis difficult to be proven. Perhaps further studies in the future will elucidate the exact mechanism, which causes this rare manifestation of EBV infection. We hope that our paper will be a motivation for our colleagues to retrospectively review unpublished or published cases of EBV-related AAC that have undergone surgery and investigate the validity of our hypothesis.

\section{Conclusion}

Acalculous cholecystitis is a well-recognized complication of EBV primary infection, and clinicians should be aware of this rare clinical entity. The female gender seems to strongly predispose for this complication. In the vast majority of the cases, inflammation subsides without the need of surgical intervention and vasculitis may be the major underlying mechanism. Further larger case series and histologic confirmation are warranted.

\section{Conflicts of Interest}

The authors declare that there are no conflicts of interest regarding the publication of this paper.

\section{References}

[1] R. Baer, A. T. Bankier, M. D. Biggin et al., "DNA sequence and expression of the B95-8 Epstein-Barr virus genome," Nature, vol. 310, no. 5974, pp. 207-211, 1984.

[2] L. S. Young and A. B. Rickinson, "Epstein-Barr virus: 40 years on," Nature Reviews Cancer, vol. 4, no. 10, pp. 757-768, 2004.

[3] O. L. Hatton, A. Harris-Arnold, S. Schaffert, S. M. Krams, and O. M. Martinez, "The interplay between Epstein-Barr virus and B lymphocytes: implications for infection, immunity, and disease," Immunologic Research, vol. 58, no. 2-3, pp. 268-276, 2014.

[4] S Wen, N. Shimizu, H. Yoshiyama, Y. Mizugaki, F. Shinozaki, and K. Takada, "Association of Epstein-Barr virus (EBV) with Sjögren's syndrome: differential EBV expression between epithelial cells and lymphocytes in salivary glands," The American Journal of Pathology, vol. 149, pp. 1511-1517, 1996. 
[5] G. S. Hoffman and W. A. Franck, "Infectious mononucleosis, autoimmunity, and vasculitis. A case report," JAMA: The Journal of the American Medical Association, vol. 241, no. 25, pp. 2735-2736, 1979.

[6] K. Yoshie, M. Ohta, N. Okabe, T. Komatsu, and S. Umemura, "Gallbladder wall thickening associated with infectious mononucleosis," Abdominal Imaging, vol. 29, no. 6, pp. 694-695, 2004.

[7] A. D. Koch, H. C. M. van den Bosch, and B. Bravenboer, "Epstein-Barr virus-associated cholecystitis," Annals of Internal Medicine, vol. 146, no. 11, pp. 826-827, 2007.

[8] C. Iaria, L. Arena, G. Di Maio et al., "Acute acalculous cholecystitis during the course of primary Epstein-Barr virus infection: a new case and a review of the literature," International Journal of Infectious Diseases, vol. 12, no. 4, pp. 391-395, 2008.

[9] P. Pelliccia, A. Savino, C. Cecamore et al., "Imaging spectrum of EBV-infection in a young patient," Journal of Ultrasound, vol. 11, no. 2, pp. 82-84, 2008.

[10] S. Hagel, T. Bruns, M. Kantowski, P. Fix, T. Seidel, and A. Stallmach, "Cholestatic hepatitis, acute acalculous cholecystitis, and hemolytic anemia: primary Epstein-Barr virus infection under azathioprine," Inflammatory Bowel Diseases, vol. 15, no. 11, pp. 1613-1616, 2009.

[11] E. Cholongitas, K. Katsogridakis, and M. Dasenaki, "Acalculous cholecystitis during the course of acute Epstein-Barr virus infection," International Journal of Infectious Diseases, vol. 13, no. 3, pp. e129-e130, 2009.

[12] H. N. Yang, K. W. Hong, J. S. Lee, and J. S. Eom, “A case of acute cholecystitis without cholestasis caused by Epstein-Barr virus in a healthy young woman," International Journal of Infectious Diseases, vol. 14, no. 5, pp. e448-e449, 2010.

[13] P. Chalupa, M. Kaspar, and M. Holub, "Acute acalculous cholecystitis with pericholecystitis in a patient with EpsteinBarr Virus infectious mononucleosis," Medical Science Monitor, vol. 15, pp. CS30-CS33, 2009.

[14] S. O. Arya, A. Saini, M. El-Baba, H. Salimnia, and N. AbdelHaq, "Epstein barr virus-associated acute acalculous cholecystitis: a rare occurrence but favorable outcome," Clinical Pediatrics, vol. 49, no. 8, pp. 799-804, 2010.

[15] A. Nagdev and J. Ward, "Bedside ultrasound diagnosis of acalculous cholecystitis from epstein-bar virus," Western Journal of Emergency Medicine, vol. 12, no. 4, pp. 481-483, 2011.

[16] V. Beltrame, A. Andres, F. Tona, and C. Sperti, "Epstein-Barr virus-associated acute acalculous cholecystitis in an adult," American Journal of Case Reports, vol. 13, pp. 153-156, 2012.

[17] J. Dylewski, "Acute acalculous cholecystitis caused by EpsteinBarr virus infection," Clinical Microbiology Newsletter, vol. 34, no. 1, pp. 7-8, 2012.

[18] M. F. Carrascosa, J.-R. S. Caviedes, G. Soler-Dorda, and C. Saiz-Perez, "Epstein-Barr virus acute cholecystitis," BMJ Case Reports, vol. 2012, 2012.

[19] E. Strehle, Y. De Alwis, and M. Saleem, "Epstein-Barr virusassociated acute cholecystitis in a teenager," Ultrasound, vol. 22, no. 2, pp. 123-125, 2014.

[20] F. Celik, F. Celik, F. Tekin, T. Yamazhan, and F. Gunsar, "Epstein-Barr virüs associated acute acalculous cholecystitis," Journal of Gastroenterology and Hepatology Research, vol. 3, pp. 1179-1180, 2014.

[21] A. Gagneux-Brunon, F. Suy, A. Pouvaret et al., "Acute acalculous cholecystitis, a rare complication of Epstein-Barr virus primary infection: report of two cases and review," Journal of Clinical Virology, vol. 61, no. 1, pp. 173-175, 2014.
[22] A. Pawlowska-Kamieniak, A. Mroczkowska-Juchkiewicz, D. Golyska, K. Kominek, and E. Pac-Kozuchowska, "Acute acalculous cholecystitis in a 17-year-old girl with Epstein-Barr virus infection," Przeglad Gastroenterologiczny, vol. 10, pp. 54-56, 2015.

[23] J. Agergaard and C. S. Larsen, "Acute acalculous cholecystitis in a patient with primary Epstein-Barr virus infection: a case report and literature review," International Journal of Infectious Diseases, vol. 35, pp. 67-72, 2015.

[24] F. Alkhoury, D. Diaz, and J. Hidalgo, "Acute acalculous cholecystitis (AAC) in the pediatric population associated with Epstein-Barr virus (EBV) infection. Case report and review of the literature," International Journal of Surgery Case Reports, vol. 11, pp. 50-52, 2015.

[25] L. Branco, M. Vieira, C. Couto, M. D. Coelho, and C. Laranjeira, "Acute acalculous cholecystitis by epstein-barr virus infection: a rare association," Infectious Disease Reports, vol. 7, p. 6184, 2015.

[26] M. Majdalani, N. Milad, Z. Sahli, and S. Rizk, "Acute acalculous cholecystitis in a Lebanese girl with primary EpsteinBarr viral infection,” BMJ Case Reports, vol. 2016, 2016.

[27] S. Ono, T. Kobayashi, and K. Nisho, "A case of acute acalculous cholecystitis during infectious mononucleosis caused by the epstein-barr virus in a young woman," Kansenshogaku Zasshi, vol. 90, no. 3, pp. 330-335, 2016.

[28] T. Koufakis and I. Gabranis, "Another report of acalculous cholecystitis in a Greek patient with infectious mononucleosis: a matter of luck or genetic predisposition?" Case Reports in Hepatology, vol. 2016, Article ID 6080832, 3 pages, 2016.

[29] F. Sheybani, H. Naderi, S. S. Erfani, and M. Gharib, "A complicated course of acute viral induced pharyngitis, icteric hepatitis, acalculous cholecystitis, and skin rash," Case Reports in Medicine, vol. 2016, Article ID 6796094, 5 pages, 2016.

[30] Z. Yesilbag, A. Karadeniz, and F. O. Kaya, "Acute acalculous cholecystitis: a rare presentation of primary Epstein-Barr virus infection in adults-case report and review of the literature," Case Reports in Infectious Diseases, vol. 2017, Article ID 5790102, 5 pages, 2017.

[31] A. Cameron, K. Akilan, and D. Carr, "Infectious mononucleosis - not always a benign condition: a case report of infectious mononucleosis-associated acute acalculous cholecystitis," CJEM, vol. 21, no. 1, pp. 1-3, 2018.

[32] P. Hohn, C. Braumann, W. Uhl, and A. M. Luu, "Riddle me this: acalculous cholecystitis as an unusual complication of immunoglobulin M negative mononucleosis," Cureus, vol. 10, Article ID e2505, 2018.

[33] K. N. Rezkallah, K. Barakat, A. Farrah et al., "Acute acalculous cholecystitis due to primary acute Epstein-Barr virus infection treated with laparoscopic cholecystectomy; a case report," Annals of Medicine and Surgery, vol. 35, pp. 189-191, 2018.

[34] M. W. Jones and T. Ferguson, Gallbladder, Cholecystitis, Acalculous, StatPearls Publishing, St. Petersburg, FL, USA, 2018.

[35] J. L. Huffman and S. Schenker, "Acute acalculous cholecystitis: a review," Clinical Gastroenterology and Hepatology, vol. 8, no. 1, pp. 15-22, 2010.

[36] H. Yasuda, T. Takada, Y. Kawarada et al., "Unusual cases of acute cholecystitis and cholangitis: tokyo guidelines," Journal of Hepato-Biliary-Pancreatic Surgery, vol. 14, no. 1, pp. 98113, 2007.

[37] J. C. Reurings, R. P. D. Diaz, L. Penninga, and D. R. Nellensteijn, "Acute acalculous cholecystitis after abdominal wall repair (rives-stoppa)," BMJ Case Reports, vol. 2014, pp. 10-12, 2014. 
[38] S. A. de Oliveira Junior, T. E. Veras Lemos, A. C. de Medeiros Junior et al., "Acute acalculous cholecystitis in critically ill patients: risk factors, diagnosis and treatment strategies," JOP: Journal of the Pancreas, vol. 17, pp. 580-586, 2016.

[39] J. Mendonça, J. Marques-Neto, P. Prando, and S. Appenzeller, "Acute acalculous cholecystitis in juvenile systemic lupus erythematosus," Lupus, vol. 18, no. 6, pp. 561-563, 2009.

[40] P. Davies and Y. Aoyagi, "Leptospirosis presenting as acute acalculous cholecystitis," Clinical Case Reports, vol. 5, no. 11, pp. 1775-1779, 2017.

[41] H. Lee, M. Ji, J.-H. Hwang et al., "Acute cholecystitis in patients with scrub typhus," Journal of Korean Medical Science, vol. 30, no. 11, pp. 1698-1700, 2015.

[42] J. Dinulos, D. K. Mitchell, J. Egerton, and L. K. Pickering, "Hydrops of the gallbladder associated with Epstein-Barr virus infection: a report of two cases and review of the literature," The Pediatric Infectious Disease Journal, vol. 13, no. 10, pp. 924-929, 1994.

[43] A. Fretzayas, M. Moustaki, A. Attilakos, T. Brozou, and P. Nicolaidou, "Acalculous cholecystitis or biliary dyskinesia for Epstein-Barr virus gallbladder involvement?” Prague Medical Report, vol. 115, no. 1-2, pp. 67-72, 2014.

[44] S. I. Myers, "The role of eicosanoids in experimental and clinical gallbladder disease," Prostaglandins, Leukotrienes and Essential Fatty Acids, vol. 45, no. 3, pp. 167-180, 1992.

[45] D. Rodà, M. Huici, S. Ricart, J. Vila, C. Fortuny, and L. Alsina, "Cholecystitis and nephrotic syndrome complicating EpsteinBarr virus primary infection," Paediatrics and International Child Health, vol. 37, no. 1, pp. 74-77, 2017.

[46] N. Keorochana, "A case report of Epstein-Barr virus-associated retinal vasculitis: successful treatment using only acyclovir therapy," International Medical Case Reports Journal, vol. 9, pp. 213-218, 2016.

[47] B. Karakayali, S. Yilmaz, D. Çakir, P. G. Günes, S. Güven, and I. Islek, "Henoch-schonlein purpura associated with primary active epstein barr virus infection: a case report," Pan African Medical Journal, vol. 27, p. 29, 2017.

[48] K. Kano, T. Katayama, S. Takeguchi et al., "Biopsy-proven case of Epstein-Barr virus (EBV)-associated vasculitis of the central nervous system," Neuropathology, vol. 37, no. 3, pp. 259-264, 2017.

[49] M. M. Barrett, M. Sangüeza, B. Werner, H. Kutzner, and J. A. Carlson, "Lymphocytic arteritis in epstein-barr virus vulvar ulceration (lipschütz disease)," The American Journal of Dermatopathology, vol. 37, no. 9, pp. 691-698, 2015.

[50] P. Xu, S. Lin, L. Wei, and W. Shang, "Antineutrophil cytoplasmic antibody-associated vasculitis associated with Epstein-Barr virus infection: a case report and review of the literature," Infection, vol. 42, no. 3, pp. 591-594, 2014.

[51] C. Guerriero, G. Moretta, G. Bersani, P. Valentini, A. Gatto, and D. Rigante, "Epstein-Barr virus-related cutaneous necrotizing vasculitis in a girl heterozygous for factor V Leiden," Journal of Dermatological Case Report, vol. 11, pp. 25-28, 2017.

[52] J. Hernández-Rodríguez, C. D. Tan, E. R. Rodríguez, and G. S. Hoffman, "Single-organ gallbladder vasculitis: characterization and distinction from systemic vasculitis involving the gallbladder. An analysis of 61 patients," Medicine, vol. 93, no. 24 , pp. 405-413, 2014. 